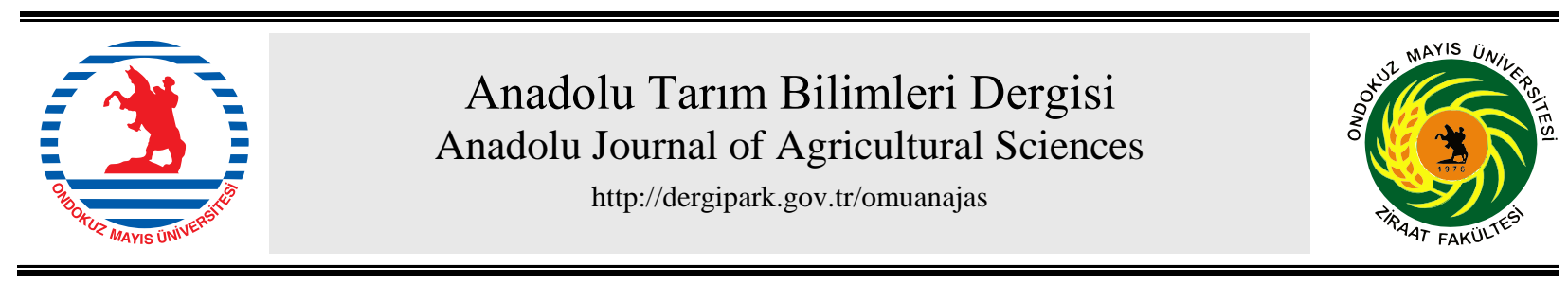

Araştırma/Research

Anadolu Tarım Bilim. Derg./Anadolu J Agr Sci, 36 (2021) ISSN: 1308-8750 (Print) 1308-8769 (Online) doi: 10.7161/omuanajas.885020

\title{
Kurt Üzümünde Çelik Alma Zamanı, Çelik Tipi ile IBA Dozlarının Kök ve Sürgün Gelişimi Üzerine Etkileri
}

\author{
• Hüseyin Çelik ${ }^{\mathrm{a}^{*}}$, ĐFigen Yayla Çetin ${ }^{\mathrm{b}}$ \\ ${ }^{a}$ Ondokuz Mayıs Üniversitesi, Ziraat Fakültesi, Bahçe Bitkileri Bölümü, Samsun-Türkiye \\ ${ }^{b}$ DSİ Bölge Müdürlüğ̈̈, Aksaray, Türkiye
}

*Sorumlu yazar/corresponding author: huscelik@omu.edu.tr

Geliş/Received 22/02/2021 Kabul/Accepted 24/05/2021

\begin{abstract}
ÖZET
Bu çalışma 2017-2018 yılları arasında yürütülmüş ve kurt üzümünün (Lycium barbarum L.) çelikle çoğaltılmasında çelik alma zamanı ile Indol-3-butrik-asit (IBA) dozlarının çeliklerdeki kök ile sürgünlerin büyüme ve gelişmesi üzerine etkileri saptanmıştır. Aksaray İli, Karkın Köyünde yetişmekte olan üç yaşındaki 2 farklı kurt üzümü çeşidine (NQ7 ve Damaye) ait bitkilerden 4 farklı zamanda (Ağustos-15, Ekim-15, Aralık-15 ve Şubat-15) alınan yarı odun ve odun çeliklerine farklı dozlarda (0, 500, 1000 ve 2000 ppm) indole-3-butryic asit (IBA) uygulanarak sera ortamında mistleme ünitesine ve perlit ortamında köklendirilmiştir. Deneme tesadüf blokları deneme desenine göre üç tekerrürlü ve her tekerrürde 25 çelik olacak şekilde kurulmuştur. Sera ortamında, alttan 1sıtmalı tavalarda köklendirilmeye alınan çeliklerde kök sayısı (adet), kök uzunluğu (cm), köklenme derecesi (1-9), sürgün uzunluğu $(\mathrm{cm})$ ve sürgün çapı $(\mathrm{mm})$ tespit edilmiştir. Deneme sonuçlarına göre Ağustos ayında alınarak 1000 ppm IBA dozu uygulanan çeliklerdeki kök sayısı (10.80), kök uzunluğu $(5.29 \mathrm{~cm})$, köklenme derecesi (6.39) ve sürgün çap1 (1.48 mm) en yüksek olmuştur. Kurt üzümü çeliklerindeki kök ve sürgün gelişimi üzerine incelenen tüm özellikler bakımından en iyi sonuçlar Damaye çeşidinden alınırken, en iyi kök ve sürgün gelişimi gösteren çeliklerin Ağustos ayında alınan yarı odunsu çelikler olduğu ve 1000 ppm IBA dozunun da en uygun doz olduğu tespit edilmiştir.
\end{abstract}

\section{The Effects of Cutting Type and IBA Doses on Root and Shoot Development in Goji Berry Cuttings}

\footnotetext{
ABSTRACT

This study was carried out between 2017-2018 and the effect of cutting collecting time and IBA doses on root and shoot growth and development of goji berry (Lycium barbarum L.) cuttings were determined. Cuttings collected three years old Damaye and NQ7 goji berry cultivars grown in Karkin Village of Aksaray Province. Semi-hardwood and hardwood cuttings collected at 4 different times (August-15, October-15, December-15 and February-15) and applied with 4 different Indole-3-butryicacid (IBA) doses $(0,500,1000$ and $2000 \mathrm{ppm})$ in bottom heated trays with perlite medium and over misting under high tunnel. They planted in trays with perlite medium under misting and bottom heating for rooting. The study planned with three replications and 25 cuttings for each replication under randomized complete block design under greenhouse. Cuttings were mowed after two months and root length $(\mathrm{cm})$, root number, rooting degree (1-9), shoot length $(\mathrm{cm})$ and diameter $(\mathrm{mm})$ were determined. According to the results of the experiment, the number of roots (10.80), root length $(5.29 \mathrm{~cm})$, rooting degree (6.39) and shoot diameter $(1.48 \mathrm{~mm}$ ) were the highest in August semi-hardwood cuttings from Damaye and with 1000 ppm IBA dose. In terms of the properties examined for root and shoot growth and development of goji berry cuttings, the best results were obtained from Damaye variety, while the best cutting taking time was August, semi-hardwood cuttings and the IBA dose was $1000 \mathrm{ppm}$.
}

\section{Anahtar Sözcükler: \\ Goji berry \\ Çoğaltma \\ Çelik tipi \\ IBA \\ Kök ve sürgün}

Keywords:

Goji berry

Propagation

Cutting type

IBA

Root and shoot

(C) OMU ANAJAS 2021 


\section{Giriş}

Anavatanı Asya olan kurt üzümü (Lycium barbarum, L.) dünyanın tropik ve subtropik bölgelerinde yetişebilen ve Solanaceae familyasına giren bir türdür (Levin ve Miller, 2005; Anonim, 2016). Goji berry veya wolfberry de denilen kurt üzümü geleneksel tıp ve gıda alanında kullanılan, kırmızı renkli ve yumuşak meyveleri olan, çalı formlu bir bitkidir (Potterat, 2010). Tropik bölgelerde bulunmakla birlikte çoğunlukla kurak ve yarı kurak bölgelerde, az da olsa hafif tuzlu alanlarda da yayılış gösteren (Fukuda ve ark., 2001) kurt üzümü bitkileri genelde dikenli çalı formunda olup, 1-4 m'ye kadar boylanırlar (Bryan ve ark., 2008). Kurt üzümü yer bakımından seçici olmamakla beraber kurak yaz günlerini tolere edebilir, hafif-kumlu, orta-kuvvetli ve ağır-killi vb. toprak tiplerinde iyi gelişim gösterir (Anonim, 2015). Kurt üzümü genellikle kurutulmuş meyve olarak tüketilir. Çikolata, pasta, tatlı, salata ve müslilere tat ve renk vermek veya pasta, kek ve kurabiyelerde kullanılmaktadır (Çelik ve Yayla Çetin, 2017). Yaşlanmayı önleyici, hücre metabolizmasını arttırıcı, cildi yenileyici ve hücre büyümesini hızlandırarak cildin canlılığını ve elastikiyetini arttırıcı özelliğinden dolayı birçok kozmetik ürününde kullanılmaya başlanmıştır. İçerdiği güçlü antioksidan ve vitaminler sayesinde güneş lekeleri, yara izleri, sivilce ve sivilce lekelerine karşı da etkili olduğu ifade edilmektedir (Yi ve Dong, 2013).

Türkiye için yeni bir bitki olan kurt üzümü fidanlarının üretilmesinde iyi tiplerden alınacak çelikler, köklendirmede kullanılacak ortam, oksin ve diğer uygulamalar konusunda temel bilgilere ihtiyaç duyulmaktadır. Kurt üzümü tohum veya yeşil aksamdan alınan çelikleriyle çoğaltılabilmektedir. Kurt üzümü tohumla çoğaltılması Yılmaz ve Kınay (2016) tarafindan belirlenmeye çalışılmıştır. Oksin uygulamasının köklenme oranını artırdığı ancak kök uzunluğunu da azalttığını ortaya koyan araştırıcılar Alsup ve ark. (2004) gibi farklı doz ve çelik alma zamanlarının denenmesi gerektiğini ifade etmişlerdir. Kurt üzümünün tohum veya vegetatif olarak çoğaltıldığını belirten Demchak (2004), tohumdan elde edilen bitkilerin fenolojik, morfolojik ve meyve özellikleri bakımından farklılıklar gösterebileceğini, tip veya çeşitlerin çelikle çoğaltılması gerektiğini belirtmektedir. Kurt üzümü olarak bilinen Lycium barbarum L.'nin iki farklı tipi ile Lycium chinense Mill'in bir tipini sert odun çelikleri ile çoğaltan Adrian ve ark. (2016), çelik kalınlığı, köklenme ortamı (torf, kum ve perlit) ile bazı hormonların (IBA 500, 100 ve 1500 ppm, Razormin ve Rhizopan) köklenme üzerine etkilerini araștırmışlardır. Çalıșmada Lycium genotiplerinde çelik kalınlığının sürgün uzunluğu ve kök hacmi üzerine olumlu etkisinin olduğu, ortamdaki torfun çeliklerdeki kök kalitesini artırdı̆̆ı, Razormin ve 1500 ppm IBA dozlarının da iyi sonuçları verdiğini ortaya koymuşlardır. Çalı formundaki bitkilerin çeliklerinin perlit:torf (3:1 v/v) ortamında iyi köklendiğini belirten Lonnee ve ark. (2011), ortamın nem içeriğinin uygun olması ve aşırı su tutmaması ve alttan 1sıtma yapılması ve köklenme ortamında 21$25^{\circ} \mathrm{C}$ arasında bir sıcaklık olması gerektiğini de bildirmektedir. İlkbahar ve yaz aylarında alınacak olan yapraklı çeliklerin mistleme sistemi altında kolayca köklendirilebileceğini belirten Hartmann ve ark. (2014), herdemyeşil veya yarı herdemyeşil özellik gösteren türlerin yaprağını döken türlere göre yapraklı çelikle çoğaltılmasında köklenmenin çok daha iyi olduğunu ve 1000-3000 ppm IBA uygulamasının da köklenmeyi olumlu bir şekilde artıracağını saptamışlardır. Araştırıcılar, Cotoneaster buxifolius türünde ise yarı odunsu çeliklere 4000-6000 ppm IBA uygulandığında ve perlit içine dikildiklerinde köklenme oranının en yüksek olarak gerçekleştiğini de tespit etmişlerdir. Çelikle çoğaltmada kullanılan çeliklerin dip kısımlarında yapılacak yaralamalar ile etiolleştirmenin de köklenme üzerine etkili olduğunu belirten Beyl ve ark. (2015), bu uygulamaların kontrole göre köklenmeyi hızlandırdığını ve çeliklerin daha kolay kök oluşturduğunu tespit etmiştir. Öte yandan köklenmesi zor olan türlerde IBA uygulaması yapılmadan köklenme olmayacağı ve yaralamaya göre etiolleştirmenin köklenme üzerine daha fazla etki ettiği de aynı araştırıcılar tarafından ortaya konulmuştur. Süs bitkileri gibi çalı formundaki bitkilerin çelikle çoğaltılmasında köklenmeyi teşvik eden oksin grubu hormonlar, çelik tipi ve çeliğin alındığı yer ile ana bitkinin yaşının yanında çeliğin dikildiği ortamın da önemli olduğunu saptayan Beyl ve ark. (2015), en iyi köklenme ortamını 3-4 kısım perlit ve 1 kısım torf veya vermikülit ile karıștırarak elde etmişlerdir.

$\mathrm{Bu}$ çalışma ile ülkemiz ekonomisi ve insan sağllğı için önemli bir gelecek vaat eden kurt üzümünün çelikle çoğaltılmasında çelik alma zamanı ile IBA dozlarının etkileri araştırılmışıı. Bu amaçla 15 Ağustos tarihinden 15 Şubat tarihine kadar iki aylık periyotlarla dört farklı zamanda alınan çelikler dört farklı IBA dozu $(0,500,1000$ ve 2000 ppm ) ile muamele edilerek çeliklerdeki kök ve sürgün gelişimi üzerine olan etkileri saptanmıştır.

\section{Materyal ve Yöntem}

Bu çalışmada Aksaray İli, Kargın Köyünde yetişmekte olan 3 yaşındaki NQ7 ve Damaye kurt üzümü çeşitlerine ait bitkilerinden 4 farklı zamanda yarı odun çeliği (Ağustos ve Ekim aylarında) ve odun çeliği (Aralık ile Şubat aylarında) şeklinde alınan $15-20 \mathrm{~cm}$ uzunluk ve $1 \mathrm{~cm}$ çapındaki odun veya yarı odun çeliklerine 4 farklı dozda (0, 500, 1000 ve $2000 \mathrm{ppm}$ ) Indole-3-butrik asit (IBA) uygulanarak alttan 1sitmalı $\left(24^{\circ} \mathrm{C}\right)$ tavalardaki perlit ortaminda köklendirmeye alınmıştır. Polietilen örtülü yüksek tünel içinde ve otomatik kontrollü mistleme sulama sistemi altında tesis edilmiş olan tavalardaki perlit ortamına dikilmiş olan çeliklerde ortam neminin \%70, sıcaklığın ise 
$22^{\circ} \mathrm{C}$ 'nin üzerinde tutulması sağlanmış, havalandırma ve gölgelendirme uygulamaları ile sera içi kontrol altına alınmıştır. Dikim tarihinden üç ay sonra sökülen çeliklerde kök sayısı (adet/çelik), kök uzunluğu (cm), köklenme derecesi (1-9; 1: Köklenmemiş, 3: Zayıf köklenme, 5: Orta derecede köklenme, 7: Kuvvetli derecede köklenme ve 9: Çok kuvvetli derecede köklenme) ile sürgün uzunluğu $(\mathrm{cm})$ ve sürgün çapı $(\mathrm{mm})$ ölçümleri yapılmıştır (Şekil 1 ve 2).

Polietilen örtülü yüksek tünelde tesadüf blokları deneme desenine göre 3 tekerrürlü olarak kurulan denemede her tekerrürde 25 çelik kullanılmıştır. Denemeden elde edilen \%'de verilere açı $(\arcsin \sqrt{ } \mathrm{x})$ transformasyonu uygulanarak istatistiki analizler bu veriler üzerinden yapılmıştır. Denemeden elde edilen veriler SPSS programı kullanılarak variyans analizine tabi tutulmuş (SPSS, 2017), ortalamalar arasındaki farklılıklar ise Duncan Çoklu Karşılaştırma Testi ile \%1 düzeyinde değerlendirilmiştir.
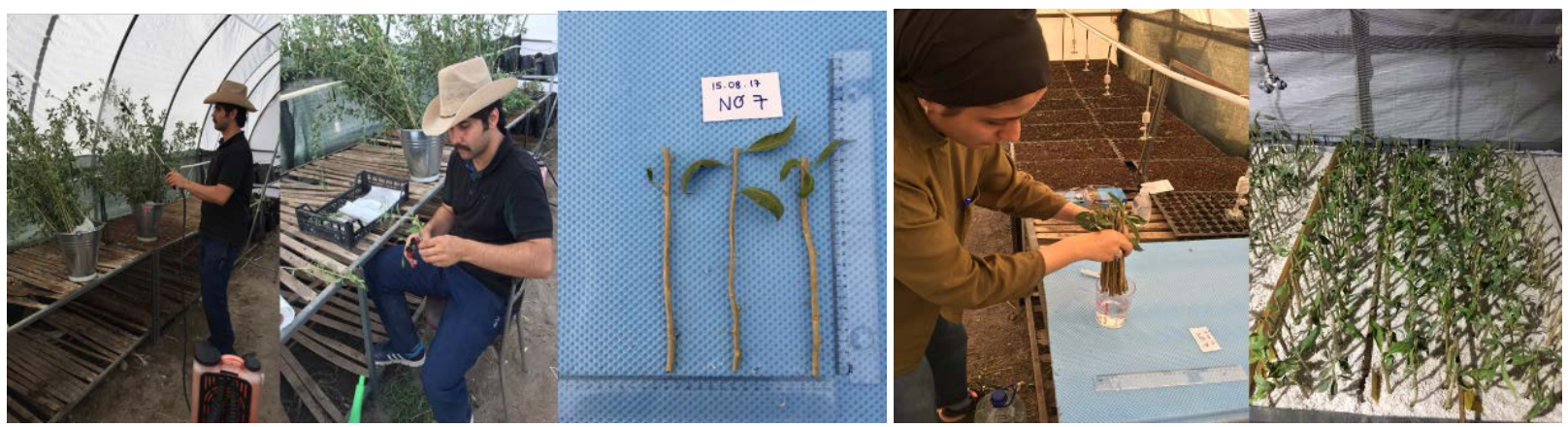

Şekil 1. Kurt üzümü çeliklerinin hazırlanması ve alttan 1sıtmalı tavalardaki perlit ortamına dikilmesi

Figure 1. Preparation of goji berry cuttings and planting into the perlite on benches with bottom heating

\section{Bulgular ve Tartışma}

Farklı zamanlarda alınarak değişik dozlarda IBA ile muamele edilmiş olan kurt üzümü (Lycium barbarum L.) çeliklerindeki kök sayısı (adet), kök uzunluğu (cm), köklenme derecesi (1-9), sürgün uzunluğu (cm) ve sürgün çapının (mm) çelik alma zamanı, IBA dozu ve çeşit interaksiyonuna göre değişimi Çizelge 1'de verilmiştir. Buna göre Damaye kurt üzümü çeşidinden Ağustos ayında alınarak 1000 ppm IBA dozu uygulanan yarı odunsu çeliklerdeki kök sayısı (10.80 adet), kök uzunluğu $(5.29 \mathrm{~cm})$, köklenme derecesi $(6.39)$ ve sürgün çapı $(1.48 \mathrm{~mm})$ bakımından en yüksek olduğu tespit edilmiştir. Sürgün uzunluğu ise yine Damaye çeşidinden ve Ağustos ayında alınan ancak 2000 ppm IBA uygulanan yarı odunsu çeliklerde $13.67 \mathrm{~cm}$ ile en yüksek değeri vermiş ancak istatistiksel olarak 1000 ppm uygulanmış çelikler ile aynı grupta yer almıştır (Çizelge 1). Öte yandan Aralık ayında Damaye çeşidinden alınan ve IBA uygulanmayan veya 2000 ppm IBA uygulanan odun çeliklerinde, NQ7 çeşidinden Aralık ayında alınarak 1000 veya 2000 ppm uygulanmış olan odun çeliklerinde köklenme olmadığ için tüm değerler sıfır olarak belirlenmiştir. Damaye çeşidinden Aralık ayında alınan ve $1000 \mathrm{ppm}$ uygulanmış olan odun çelikleri ile NQ7 çeşidinden Aralık ve Şubat ayında alınarak kontrol ile 500 ppm IBA uygulanmış olan odun çeliklerinde de sürme meydana gelmediği saptanmıştır (Çizelge 1).

Çeşit ve çelik alma zamanları etkileşimine göre Damaye kurt üzümü çeşidinden Ağustos ayında alınan yarı odunsu çeliklerdeki kök sayısı (8.53 adet), kök uzunluğu $(4.21 \mathrm{~cm})$, köklenme derecesi (4.67), sürgün uzunluğu $(11.22 \mathrm{~cm})$ ve sürgün çapı $(1.40 \mathrm{~mm})$ en yüksek iken, Damaye çeşidinden Aralık ayında alınan odun çeliklerdeki kök sayısı (0.39 adet), kök uzunluğu $(0.20 \mathrm{~cm})$ ve köklenme derecesi (1.05) en düşük olmuştur. NQ7 çeşidinden Aralık ayında alınmış olan odun çeliklerinde ise sürme meydana gelmemiştir (Çizelge 2).

Çeşit ve IBA dozları dikkate alındığında ise 1000 ppm IBA dozu uygulanan Damaye çeşidinden alınan çeliklerdeki kök sayısı (4.87 adet), kök uzunluğu $(2.81 \mathrm{~cm})$, köklenme derecesi $(2.70)$ ve sürgün uzunluğu $(5.72 \mathrm{~cm})$ en yüksek değerleri verdiği ortaya konulmuştur. Sürgün çapı bakımından çeşit x IBA doz interaksiyonları arasında istatistiki fark olmamasına rağmen NQ7 çeşidinden alınan ve 500 ppm IBA uygulanmış olan çeliklerde $0.99 \mathrm{~mm}$ sürgün çapının en yüksek olduğu ortaya konulmuştur. Damaye ile NQ7 çeşidinden alınarak IBA uygulanmayan kontrol çeliklerindeki kök ve sürgün özellikleri en düşük seviyede kalmıştır (Çizelge 3).

Çelik alma zamanı ve IBA doz interaksiyonuna dikkate alındığında ise Ağustos x 2000 ppm IBA uygulamasının yapıldığı çeliklerdeki kök sayısı $(9.87$ adet), kök uzunluğu $(4.24 \mathrm{~cm})$ ve sürgün uzunluğu $(11.15 \mathrm{~cm})$ bakımından öne çıkarken, köklenme derecesi (4.89) ve sürgün çapı bakımından ise Ağustos ayında alınarak 1000 ppm IBA uygulanmış olan çeliklerin öne çıktığı belirlenmiştir. Aralık ayında alınarak IBA uygulanmış veya uygulanmamış odun çeliklerindeki incelenen tüm özelliklerin ise sıfır veya sıfıra yakın olduğu da belirlenmiştir (Çizelge 4). 
Çizelge 1. Farklı çeşitlerinden değişik zamanlarda alınarak farklı IBA konsantrasyonları ile muamele edilen kurt üzümü çeliklerinde kök sayısı (adet), kök uzunluğu (cm), köklenme derecesi (1-9), sürgün uzunluğu (cm) ve sürgün çapının (mm) çelik alma zamanı, IBA dozu ve çeşitlere göre değişimi

Table 1. The root number and length $(\mathrm{cm})$, rooting degree (1-9), shoot length $(\mathrm{cm})$ and diameter $(\mathrm{mm})$ of goji berry cuttings taken in different times and applied with different IBA doses.

\begin{tabular}{|c|c|c|c|c|c|c|c|}
\hline Çeşit & Zaman & IBA & $\begin{array}{c}\text { Kök say1s1 } \\
\text { (Adet) }\end{array}$ & $\begin{array}{c}\text { Kök } \\
\text { uzunluğu } \\
\text { (cm) }\end{array}$ & $\begin{array}{c}\text { Köklenme } \\
\text { Derecesi } \\
(1-9)^{* *}\end{array}$ & $\begin{array}{c}\text { Sürgün } \\
\text { Uzunluğu }(\mathrm{cm})\end{array}$ & $\begin{array}{c}\text { Sürgün } \\
\text { Çap1 } \\
\text { (mm) }\end{array}$ \\
\hline \multirow{16}{*}{ Damaye } & \multirow{3}{*}{ Ağustos } & 0 & 5.46 & 3.17 bcd* $^{*}$ & $3.35 \mathrm{c}$ & 7.93 bcd* $^{*}$ & $1.39 \mathrm{ab}^{*}$ \\
\hline & & 500 & 7.73 & 3.16 bcd & $4.57 \mathrm{~b}$ & $9.84 \mathrm{ab}$ & $1.37 \mathrm{ab}$ \\
\hline & & 1000 & 10.80 & $5.29 \mathrm{a}$ & $6.39 \mathrm{a}$ & $13.42 \mathrm{a}$ & $1.48 \mathrm{a}$ \\
\hline & \multirow{5}{*}{ Ekim } & 2000 & 10.14 & $5.20 \mathrm{a}$ & $4.36 \mathrm{~b}$ & $13.67 \mathrm{a}$ & $1.37 \mathrm{ab}$ \\
\hline & & 0 & 0.00 & $0.00 \mathrm{k}$ & $1.00 \mathrm{e}$ & $0.00 \mathrm{~g}$ & $0.00 \mathrm{e}$ \\
\hline & & 500 & 1.91 & 0.83 g-k & $1.37 \mathrm{e}$ & $2.75 \mathrm{~d}-\mathrm{g}$ & 0.79 a-e \\
\hline & & 1000 & 4.67 & 1.90 c-i & $2.20 \mathrm{~d}$ & $5.71 \mathrm{~b}-\mathrm{f}$ & $1.34 \mathrm{ab}$ \\
\hline & & 2000 & 2.56 & $1.21 \mathrm{e}-\mathrm{j}$ & $1.24 \mathrm{e}$ & $4.21 \mathrm{c}-\mathrm{g}$ & $0.89 \mathrm{bcd}$ \\
\hline & \multirow{4}{*}{ Aralık } & 0 & 0.00 & $0.00 \mathrm{k}$ & $1.00 \mathrm{e}$ & $0.00 \mathrm{~g}$ & $0.00 \mathrm{e}$ \\
\hline & & 500 & 0.58 & $0.35 \mathrm{jk}$ & $1.11 \mathrm{e}$ & $2.05 \mathrm{efg}$ & 0.45 cde \\
\hline & & 1000 & 1.00 & $0.44 \mathrm{ijk}$ & $1.11 \mathrm{e}$ & $0.00 \mathrm{~g}$ & $0.00 \mathrm{e}$ \\
\hline & & 2000 & 0.00 & $0.00 \mathrm{k}$ & $1.00 \mathrm{e}$ & $0.00 \mathrm{~g}$ & $0.00 \mathrm{e}$ \\
\hline & \multirow{4}{*}{ Şubat } & 0 & 1.67 & $1.71 \mathrm{~d}-\mathrm{j}$ & $1.11 \mathrm{e}$ & $5.00 \mathrm{~b}-\mathrm{g}$ & 0.85 a-e \\
\hline & & 500 & 3.00 & 3.33 bc & $1.11 \mathrm{e}$ & $0.00 \mathrm{~g}$ & $0.00 \mathrm{e}$ \\
\hline & & 1000 & 3.00 & $3.61 \mathrm{~b}$ & $1.11 \mathrm{e}$ & 3.77 c-g & 0.84 a-e \\
\hline & & 2000 & 1.22 & 0.81 g-k & $1.13 \mathrm{e}$ & $2.08 \mathrm{efg}$ & 0.59 b-e \\
\hline \multirow{16}{*}{ NQ7 } & \multirow{3}{*}{ Ağustos } & 0 & 3.33 & $1.73 \mathrm{~d}-\mathrm{j}$ & $1.35 \mathrm{e}$ & $5.23 \mathrm{~b}-\mathrm{g}$ & $1.29 \mathrm{ab}$ \\
\hline & & 500 & 3.33 & $2.56 \mathrm{~b}-\mathrm{f}$ & $2.15 \mathrm{~d}$ & $10.13 \mathrm{ab}$ & $1.29 \mathrm{ab}$ \\
\hline & & 1000 & 6.07 & $2.92 \mathrm{bcd}$ & $3.40 \mathrm{c}$ & 7.03 b-e & $1.41 \mathrm{ab}$ \\
\hline & \multirow{5}{*}{ Ekim } & 2000 & 9.60 & 3.27 bc & $4.17 \mathrm{~b}$ & $8.63 \mathrm{abc}$ & $1.37 \mathrm{ab}$ \\
\hline & & 0 & 1.33 & 0.97 g-k & $1.16 \mathrm{e}$ & $8.53 \mathrm{abc}$ & 1.25 abc \\
\hline & & 500 & 2.25 & $1.08 \mathrm{f}-\mathrm{k}$ & $1.24 \mathrm{e}$ & 5.95 b-f & $1.34 \mathrm{ab}$ \\
\hline & & 1000 & 3.17 & 0.45 h-k & $1.11 \mathrm{e}$ & $1.47 \mathrm{fg}$ & 0.42 cde \\
\hline & & 2000 & 1.73 & $1.32 \mathrm{e}-\mathrm{k}$ & $1.19 \mathrm{e}$ & $1.38 \mathrm{fg}$ & 0.42 cde \\
\hline & \multirow{4}{*}{ Aralık } & 0 & 1.40 & $1.99 \mathrm{c}-\mathrm{h}$ & $1.19 \mathrm{e}$ & $0.00 \mathrm{~g}$ & $0.00 \mathrm{e}$ \\
\hline & & 500 & 1.00 & $0.53 \mathrm{~h}-\mathrm{k}$ & $1.05 \mathrm{e}$ & $0.00 \mathrm{~g}$ & $0.00 \mathrm{e}$ \\
\hline & & 1000 & 0.00 & $0.00 \mathrm{k}$ & $1.00 \mathrm{e}$ & $0.00 \mathrm{~g}$ & $0.00 \mathrm{e}$ \\
\hline & & 2000 & 0.00 & $0.00 \mathrm{k}$ & $1.00 \mathrm{e}$ & $0.00 \mathrm{~g}$ & $0.00 \mathrm{e}$ \\
\hline & \multirow{4}{*}{ Şubat } & 0 & 4.64 & 2.71 b-e & $1.32 \mathrm{e}$ & $0.00 \mathrm{~g}$ & $0.00 \mathrm{e}$ \\
\hline & & 500 & 4.28 & $3.01 \mathrm{bcd}$ & $1.29 \mathrm{e}$ & $5.23 \mathrm{~b}-\mathrm{g}$ & $1.32 \mathrm{ab}$ \\
\hline & & 1000 & 2.50 & 2.26 b-g & $1.16 \mathrm{e}$ & $1.83 \mathrm{efg}$ & $0.40 \mathrm{de}$ \\
\hline & & 2000 & 2.78 & $2.99 \mathrm{bcd}$ & $1.19 \mathrm{e}$ & $0.00 \mathrm{~g}$ & $0.00 \mathrm{e}$ \\
\hline
\end{tabular}

*Aynı sütunda yer alan ve aynı harf ile işaretli olan ortalamalar arasında \%1'e göre fark yoktur.

**1-9 skalası : 1=Köklenme yok. 3=Zayıf köklenme. 5=Orta derecede köklenme. 7=Kuvvetli derecede köklenme ve 9=çok kuvvetli derecede köklenme

Kurt üzümünün tohum ve in vitro koşullarda doku kültürü ile çoğaltılması pratik olarak çok tercih edilmememekle birlikte, en çok tercih edilen çoğaltma yöntemi çelikle çoğaltmadır. Çelikle çoğaltılabilen kurt üzümünde ise yeşil çeliklerin tercih edilmediği ve yaz aylarında alınan yarı odunsu veya kış aylarında alınan odun çelikleri ile çoğaltılabileceği belirtilmektedir. Ayrıca, çeliklere köklenmeyi artıran oksin grubu büyümeyi düzenleyici maddelerin uygulanması da köklenme başarısını arttırdığı saptanmıştır (Adrian ve ark., 2016).

Kurt üzümü bitkisinin çelikle çoğaltılmasında köklenmenin yanında kök kalitesi için köklerin uzunluğu, çapı, kök sayısı ve kapladıkları hacim ile köklenme derecelerine de bakılmaktadır. Alttan 1sıtmalı tavalarda perlit ortamında köklendirdiğimiz kurt üzümü çeliklerinde çeşit, çelik alma zamanı ve IBA dozu uygulamalarının kök uzunluklarına etkisi de oldukça önemli olmuştur. Nitekim Damaye kurt üzümü çeşidinden Ağustos ayında alınarak 1000 ppm IBA dozu uygulanan yarı odunsu çelikler en uzun kök uzunluğuna $(5.29 \mathrm{~cm})$ ulaşmışlardır. Bununla birlikte, Damaye çeşidinden Ekim ayında alınarak IBA uygulanmayan odun çelikleri ile Aralık ayında alınan ve kontrol grubu ile 2000 ppm IBA uygulanan odun çeliklerinde köklenme olmadığ için kök uzunluğu $0.00 \mathrm{~cm}$ ile en düşük olmuştur. NQ7 çeşidi kurt üzümü çelikleri incelendiğinde ise Aralık ayında alınarak 1000 ve 2000 ppm IBA dozu uygulanan odun çeliklerinde hiç köklenme olmamış ve kök uzunlukları $0.00 \mathrm{~cm}$ ile en düşük seviyede kalmıştır (Çizelge 1). Çeliklerdeki kök sayısı, kök uzunluğu, köklenme derecesi, sürgün uzunluk ve çapının da kurt 
üzümü çeşitlerine göre farklı olduğu ve Damaye çeşidine ait çeliklerdeki verilerin (sırasıyla 3.36 adet, 1.94 cm, 2.07, $4.40 \mathrm{~cm}$ ve $0.71 \mathrm{~mm}$ ) NQ7 çeşidine göre daha yüksek olduğu saptanmıştır (Şekil 3).

Çizelge 2. Farklı çeşitlerinden değişik zamanlarda alınarak farklı IBA konsantrasyonları ile muamele edilen kurt üzümü çeliklerinde kök sayısı (adet), kök uzunluğu (cm), köklenme derecesi (1-9), sürgün uzunluğu (cm) ve sürgün çapının $(\mathrm{mm})$ çelik alma zamanı ve çeşitlere göre değişimi

Table 2. The variaton of root number and length $(\mathrm{cm})$, rooting degree (1-9), shoot length $(\mathrm{cm})$ and diameter $(\mathrm{mm})$ according to the cultivar and cutting time of goji berry cuttings

\begin{tabular}{ccccccc}
\hline Çeşit & Zaman & $\begin{array}{c}\text { Kök sayıs1 } \\
\text { (Adet) }\end{array}$ & $\begin{array}{c}\text { Kök } \\
\text { uzunluğu } \\
(\mathrm{cm})\end{array}$ & $\begin{array}{c}\text { Köklenme } \\
\text { Derecesi } \\
(1-9) * *\end{array}$ & $\begin{array}{c}\text { Sürgün } \\
\text { Uzunluğu } \\
(\mathrm{cm})\end{array}$ & $\begin{array}{c}\text { Sürgün Çap1 } \\
(\mathrm{mm})\end{array}$ \\
\hline \multirow{3}{*}{ Damaye } & A ğustos & $8.53 \mathrm{a} *$ & $4.21 \mathrm{a}^{*}$ & $4.67 \mathrm{a}^{*}$ & $11.22 \mathrm{a}$ & 1.40 \\
& Ekim & $2.28 \mathrm{~cd}$ & $0.99 \mathrm{c}$ & $1.45 \mathrm{c}$ & $3.17 \mathrm{~cd}$ & 0.76 \\
& Aralik & $0.39 \mathrm{e}$ & $0.20 \mathrm{c}$ & $1.05 \mathrm{c}$ & $0.51 \mathrm{de}$ & 0.11 \\
& Şubat & $2.22 \mathrm{~cd}$ & $2.36 \mathrm{~b}$ & $1.11 \mathrm{c}$ & $2.71 \mathrm{cde}$ & 0.57 \\
\cline { 2 - 7 } NQ7 & Ağustos & $5.58 \mathrm{~b}$ & $2.62 \mathrm{~b}$ & $2.77 \mathrm{~b}$ & $7.76 \mathrm{~b}$ & 1.33 \\
& Ekim & $2.12 \mathrm{cde}$ & $0.96 \mathrm{c}$ & $1.17 \mathrm{c}$ & $4.33 \mathrm{c}$ & 0.86 \\
& Aralı & $0.60 \mathrm{de}$ & $0.63 \mathrm{c}$ & $1.06 \mathrm{c}$ & $0.00 \mathrm{e}$ & 0.00 \\
& Şubat & $3.55 \mathrm{c}$ & $2.74 \mathrm{~b}$ & $1.24 \mathrm{c}$ & $1.77 \mathrm{cde}$ & 0.43 \\
\hline
\end{tabular}

* Aynı sütunda yer alan ve aynı harf ile işaretli olan ortalamalar arasında \%1'e göre fark yoktur.

**1-9 skalası : 1=Köklenme yok. 3=Zayıf köklenme. 5=Orta derecede köklenme. 7=Kuvvetli derecede köklenme ve 9=çok kuvvetli derecede köklenme

Çizelge 3. Farklı çeşitlerinden değişik zamanlarda alınarak farklı IBA konsantrasyonları ile muamele edilen kurt üzümü çeliklerinde kök sayısı (adet), kök uzunluğu (cm), köklenme derecesi (1-9), sürgün uzunluğu (cm) ve sürgün çapının $(\mathrm{mm})$ çeşit ve IBA dozlarına göre değişimi

Table 3. The variaton of root number and length $(\mathrm{cm})$, rooting degree (1-9), shoot length $(\mathrm{cm})$ and diameter $(\mathrm{mm})$ according to the cultivar and IBA doses of goji berry cuttings

\begin{tabular}{ccccccc}
\hline Çeşit & IBA & $\begin{array}{c}\text { Kök say1s1 } \\
\text { (Adet) }\end{array}$ & $\begin{array}{c}\text { Kök uzunluğu } \\
(\mathrm{cm})\end{array}$ & $\begin{array}{c}\text { Köklenme } \\
\text { Derecesi } \\
(1-9)^{* *}\end{array}$ & $\begin{array}{c}\text { Sürgün } \\
\text { Uzunluğu } \\
(\mathrm{cm})\end{array}$ & $\begin{array}{c}\text { Sürgün } \\
\text { Çap1 } \\
(\mathrm{mm})\end{array}$ \\
\hline \multirow{3}{*}{ Damaye } & 0 & $1.78 \mathrm{~b}^{*}$ & $1.22 \mathrm{~b}^{*}$ & $1.61 \mathrm{ab}$ & 3.23 & 0.56 \\
& 100 & $3.31 \mathrm{ab}$ & $1.92 \mathrm{ab}$ & $2.04 \mathrm{ab}$ & 3.66 & 0.65 \\
& 2000 & $4.87 \mathrm{a}$ & $2.81 \mathrm{a}$ & $2.70 \mathrm{a}$ & 5.72 & 0.92 \\
& 0 & $3.48 \mathrm{ab}$ & $1.80 \mathrm{ab}$ & $1.93 \mathrm{ab}$ & 4.99 & 0.71 \\
\hline \multirow{2}{*}{ NQ7 } & 500 & $2.68 \mathrm{ab}$ & $1.85 \mathrm{ab}$ & $1.25 \mathrm{~b}$ & 3.44 & 0.63 \\
& 1000 & $2.71 \mathrm{ab}$ & $1.80 \mathrm{ab}$ & $1.43 \mathrm{ab}$ & 5.33 & 0.99 \\
& 2000 & $2.93 \mathrm{ab}$ & $1.41 \mathrm{ab}$ & $1.67 \mathrm{ab}$ & 2.58 & 0.56 \\
& $3.53 \mathrm{ab}$ & $1.90 \mathrm{ab}$ & $1.89 \mathrm{ab}$ & 2.50 & 0.45 \\
\hline
\end{tabular}

* Aynı sütunda yer alan ve aynı harf ile işaretli olan ortalamalar arasında \%1'e göre fark yoktur.

**1-9 skalası : 1=Köklenme yok. 3=Zayıf köklenme. 5=Orta derecede köklenme. 7=Kuvvetli derecede köklenme ve 9=çok kuvvetli derecede köklenme

Çelik alma zamanı bakımından incelenen tüm özellikler açısından Ağustos ayı çeliklerinin diğer zamanlara göre çok daha yüksek değerlere ulaştığı, daha sonraki aylarda alınmış olan çeliklerin tüm özellikler bakımından daha düşük değerler verdiği ve özellikle Aralık ayında alınan çeliklerdeki değerlerin en düşük değerlere ulaştığı ortaya konulmuştur (Şekil 4). Buna göre Ağustos ayı çeliklerinin 7.06 adet köke sahip olduğu, $3.41 \mathrm{~cm}$ kök uzunluğuna ulaştıkları, köklenme derecesinin 3.71 ile zayıf-orta derecede bir köklenme gösterdikleri, sürgün uzunluklarının 9.49 cm'ye ulaştığı ve 1.37 mm'lik bir sürgün çapı oluşturdukları saptanmıştır. Öte yandan Aralık ayında alınan çeliklerin kök ve sürgün gelişimi bakımından en düşük rakamlarda kaldığı da tespit edilmiştir (Şekil 4).

Denemede kullanılan ve köklenmeyi teşvik etmek amacıyla kurt üzümü çeliklerine uygulanan IBA dozları arasında kök sayısı ve köklenme derecesi bakımından istatistiki olarak önemli farklılıklar olduğu tespit edilmiştir. Buna göre 1000 ppm IBA uygulanmış çeliklerdeki kök sayısı (3.90 adet), kök uzunluğu $(2.11 \mathrm{~cm})$ ve köklenme derecesi (2.18) bakımından en iyi sonuçları verirken sürgün uzunluk ve çapı 500 ppm de daha yüksek olmuştur. Kontrol yani 0 ppm IBA dozu ise en düşük değerleri vermiştir (Şekil 5).

$\mathrm{Bu}$ sonuçlar değerlendirildiğinde kök uzunluklarının çeliklerin alındığı çeşit, IBA uygulaması ve çelik alma zamanlarına göre değişebileceği görülmektedir. Çelik ve Karasakal (2018), yayılıcı dağ muşmulasının tohum ve çelikle çoğaltılması amacıyla yaptıkları çalışmada, Ağustos ayında alınarak 1000 ppm IBA uyguladıktan sonra torf 
ortamına dikilen yayılıcı dağ muşmulası çeliklerin $8.64 \mathrm{~cm}$ ile en uzun kökleri verdiğini belirtmektedirler. Bu sonuçlar yaptığımız çalışma ile paralellik göstermektedir. Ayrıca herdemyeşil olan karayemiş tiplerinde kök uzunluklarının çelik alma zamanı ile IBA dozlarına göre değişebileceği Çelik ve ark. (2015) tarafından da ortaya konulmuştur. Hartmann ve ark. (2014) ise çelik alınan damızlık bitkinin yaşı, çelik alma zamanı ve oksin uygulamalarının çelikteki kök kalitesini (uzunluk ve sayı) etkileyebileceğini ve bu durumun ortam tipi ile sıcaklığa da bağlı olduğunu belirtmektedir. Denemedeki kök uzunluğu sonuçlarımız, çeliklerdeki kök uzunluğunun çelik alma zamanı, IBA dozu, genotip, çeliğin alındığı bitkinin taç pozisyonu, çelik tipi (basit ve ökçeli), çelik uzunluğu ve damızlık bitki yaşına (Brock, 2014), damızlık bitkinin bulunduğu lokasyona, bölgeye ve kullanılan oksin tipine (Alsup ve ark., 2004; Beyl ve ark., 2015) göre değişebileceğini bildiren araştırıcıların sonuçlarına paralellik göstermiştir. Nitekim bazı çalı türü bitkileri çelikle çoğaltan Yılmaz ve Yıldız (2020), 2000-8000 ppm IBA uyguladıkları çeliklerdeki kök gelişimi üzerine bitki türlerine göre farklı etki yaptığını da saptamışlardır. Denememizde ise farklı zamanlarda alınan çeliklerdeki kök gelişimi üzerine IBA dozlarının etkilerinin de farklı olduğu tespit edilmiştir.

Çizelge 4. Farklı çeşitlerinden değişik zamanlarda alınarak farklı IBA konsantrasyonları ile muamele edilen kurt üzümü çeliklerinde kök sayısı (adet), kök uzunluğu (cm), köklenme derecesi (1-9), sürgün uzunluğu (cm) ve sürgün çapının $(\mathrm{mm})$ çelik alma zamanı ve IBA dozlarına göre değişimi

Table 4. The variaton of root number and length $(\mathrm{cm})$, rooting degree (1-9), shoot length $(\mathrm{cm})$ and diameter $(\mathrm{mm})$ according to the cutting taking time and IBA doses of goji berry cuttings

\begin{tabular}{|c|c|c|c|c|c|c|}
\hline Zaman & IBA & $\begin{array}{c}\text { Kök sayısı } \\
\text { (Adet) }\end{array}$ & $\begin{array}{c}\text { Kök } \\
\text { uzunluğu } \\
(\mathrm{cm})\end{array}$ & $\begin{array}{c}\text { Köklenme } \\
\text { Derecesi } \\
(1-9)^{* *}\end{array}$ & $\begin{array}{l}\text { Sürgün } \\
\text { Uzunluğu } \\
(\mathrm{cm})\end{array}$ & $\begin{array}{c}\text { Sürgün } \\
\text { Çap1 } \\
\text { (mm) }\end{array}$ \\
\hline \multirow{3}{*}{ Ağustos } & 0 & $4.40 \mathrm{bc}^{*}$ & 2.45 & $2.35 c^{*}$ & 6.58 & 1.34 \\
\hline & 500 & $5.53 \mathrm{~b}$ & 2.86 & $3.36 \mathrm{~b}$ & 9.99 & 1.33 \\
\hline & 1000 & $8.44 \mathrm{a}$ & 4.11 & $4.89 \mathrm{a}$ & 10.28 & 1.44 \\
\hline \multirow{5}{*}{ Ekim } & 2000 & $9.87 \mathrm{a}$ & 4.24 & $4.27 \mathrm{a}$ & 11.15 & 1.37 \\
\hline & 0 & $0.67 \mathrm{def}$ & 0.49 & $1.08 \mathrm{~d}$ & 4.27 & 0.62 \\
\hline & 500 & $2.08 \mathrm{c}-\mathrm{f}$ & 0.96 & $1.31 \mathrm{~d}$ & 4.35 & 1.07 \\
\hline & 1000 & 3.92 bc & 1.18 & $1.65 \mathrm{~cd}$ & 3.59 & 0.88 \\
\hline & 2000 & $2.15 \mathrm{c}-\mathrm{f}$ & 1.27 & $1.21 \mathrm{~d}$ & 2.80 & 0.65 \\
\hline \multirow{3}{*}{ Aralık } & 0 & 0.70 def & 0.10 & $1.09 \mathrm{~d}$ & 0.00 & 0.00 \\
\hline & 500 & 0.79 def & 0.44 & $1.08 \mathrm{~d}$ & 1.02 & 0.23 \\
\hline & 1000 & 0.50 ef & 0.22 & $1.05 \mathrm{~d}$ & 0.00 & 0.00 \\
\hline \multirow{5}{*}{ Şubat } & 2000 & $0.00 \mathrm{f}$ & 0.00 & $1.00 \mathrm{~d}$ & 0.00 & 0.00 \\
\hline & 0 & 3.16 bcd & 2.13 & $1.21 \mathrm{~d}$ & 2.50 & 0.43 \\
\hline & 500 & 3.64 bc & 3.17 & $1.20 \mathrm{~d}$ & 2.61 & 0.66 \\
\hline & 1000 & 2.75 cde & 2.93 & $1.13 \mathrm{~d}$ & 2.80 & 0.62 \\
\hline & 2000 & $2.00 \mathrm{c}-\mathrm{f}$ & 1.90 & $1.16 \mathrm{~d}$ & 1.04 & 0.30 \\
\hline
\end{tabular}

*Aynı sütunda yer alan ve aynı harf ile işaretli olan ortalamalar arasında \%1'e göre fark yoktur.

**1-9 skalas1 : 1=Köklenme yok. 3=Zayıf köklenme. 5=Orta derecede köklenme. 7=Kuvvetli derecede köklenme ve 9=çok kuvvetli derecede köklenme

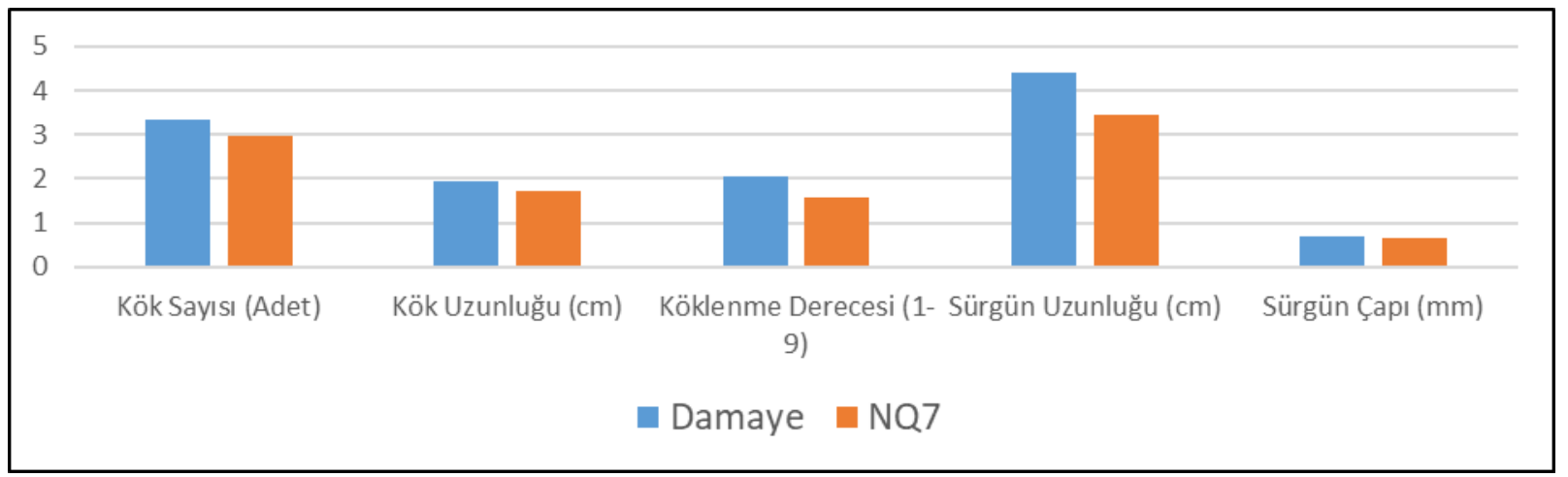

Şekil 3. Goji berry çeliklerindeki kök sayısı, kök uzunluğu, köklenme derecesi, sürgün uzunluğu ve çapının çeşitlere göre değişimi

Figure 3. Variation of root number, root length, rooting degree, shoot length and diameter according to varieties in goji berry cuttings 


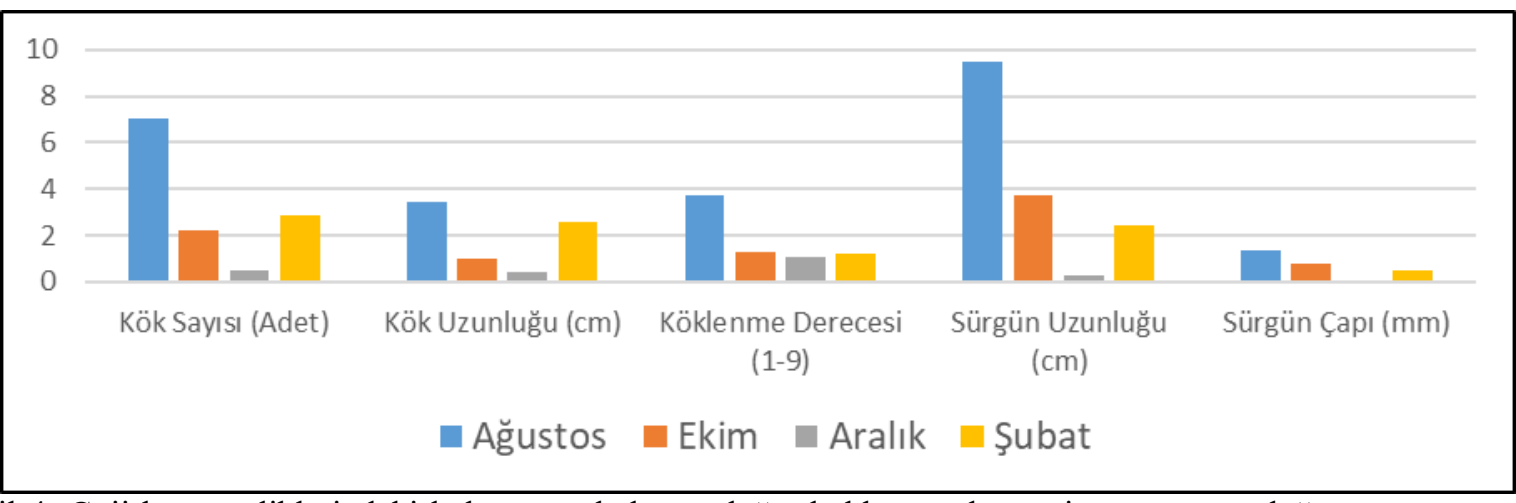

Şekil 4. Goji berry çeliklerindeki kök sayısı, kök uzunluğu, köklenme derecesi, sürgün uzunluğu ve çapının çelik alma zamanlarına göre değişimi

Figure 4. Variation of root number, root length, rooting degree, shoot length and diameter according to cutting time in goji berry cuttings

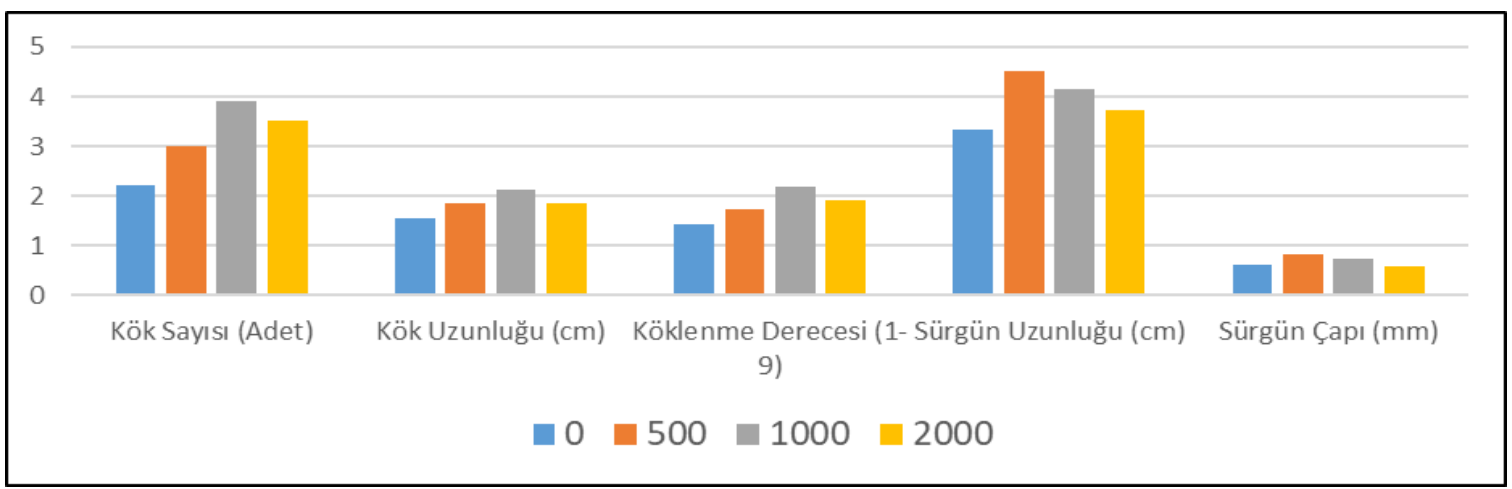

Şekil 5. Goji berry çeliklerindeki kök sayısı, kök uzunluğu, köklenme derecesi, sürgün uzunluğu ve çapının IBA dozlarına göre değişimi

Figure 5. Variation of root number, root length, rooting degree, shoot length and diameter according to IBA doses in goji berry cuttings

Vejetatif çoğaltma yöntemleri arasında en çok tercih edilen çelikle çoğaltma yönteminde köklenme oranındaki başarıya ek olarak köklenmiş olan çeliklerin oluşturdukları kök sayısı, çapı, uzunluk ve kapladıkları alanın yanı sıra yaş ve kuru kök ağırlıklarına da bakılarak kök kalitesi ortaya konulmaktadır. Bu kalite özelliklerinden kök sayısı da oldukça önem arz etmekte olup, denememiz sonuçlarına göre Damaye kurt üzümü çeşidinden Ağustos ayında alınarak 1000 ppm IBA dozu uygulanmış olan çeliklerdeki kök sayısı 10.80 adet ile en fazla olmuştur. Bununla birlikte Damaye çeşidinden Ekim ayında alınan ve IBA uygulanmayan ve Aralık ayında alınarak 0 eya 2000 ppm IBA dozu uygulanan çeliklerde köklenme olmamış ve kök sayısı sıfır olarak kaydedilmiştir. Bu sonuçları NQ7 çeşidi açısından değerlendirecek olursak Ağustos ayında alınarak 2000 ppm IBA uygulanan yarı odunsu çeliklerdeki kök sayısı 9.60 adet ile en fazla olmuştur. Fakat Aralık ayında alınan odun çeliklerinde 1000 ve 2000 ppm IBA dozu uygulanan çeliklerde köklenme meydana gelmediği için kök sayısı sıfır olarak kaydedilmiştir (Çizelge 1). Nitekim çeliklerdeki kök sayısının alttan ısıtma sıcaklığına (Ball ve Zylstra, 1998), çelik alma zamanı (Çelik ve ark., 2015; Ruter, 2015), IBA dozuna (Çelik ve ark., 2016; Ersoy ve ark., 2016), genotipe, çeliğin alındığı bitkinin taç pozisyonu ve çelik tipine (basit ve ökçeli), çelik uzunluğu ve damızlık bitkinin yaşına (Henry ve ark., 1992) göre değişebileceği bilinmektedir.

Çelik ile çoğaltılan ve kültürü yapılan bir çok bahçe bitkisinde kök sayısı, kök uzunluğu ve çapı ile köklerin çeliğin dip kısmındaki yayılışı ve yan dallanma gösterme durumu dikkate alınarak köklenme derecesi skala değerleri (1-9) oluşturulmakta ve köklenme dereceleri rakmasal olarak hesaplanmaktadır (Çelik ve ark., 2015; Çelik ve ark., 2016; Çelik ve Çelik, 2017). Skala değerleri olan 1-9’a göre hesaplanan köklenme derecesinde 1, 3, 5, 7 ve 9 rakamları sırasıyla köklenme olmadığını, zayıf, orta, kuvvetli ve çok kuvvetli köklenme olduğunu göstermektedir. Buna göre yaptığımız çalışmada kullanılan tüm faktörler (Çeşit x Zaman x IBA dozu) dikkate alındığında Damaye 
kurt üzümü çeşidinden Ağustos ayında alınarak 1000 ppm IBA dozu uygulanan yarı odunsu çeliklerin “ortakuvvetli" arasında ve 6.39'luk bir köklenme derecesi ile en yüksek köklenme derecesi değerine ulaştığı saptanmıştır. Öte yandan, Damaye kurt üzümü çeşidinden Ekim ayında alınarak IBA uygulanmayan kontrol grubu çelikleri ile Aralık ayında alınarak 0 ve 2000 ppm IBA dozu uygulanan çelikler ile NQ7 çeşidinden Aralık ayında alınarak 1000 ve 2000 ppm IBA dozu uygulanmış çeliklerdeki köklenme derecesi 1.00 değeri ile "köklenme yok" şeklinde en düşük seviyede kaydedilmiştir (Çizelge 1). Çelik alma zamanı ve IBA dozu etkileşiminde Ağustos ayında alınarak 1000 ppm IBA uygulanan yarı odunsu çeliklerde "zayıf-orta" (4.89) köklenme derecesi ile öne çıkarken Aralık ayında alınarak 2000 ppm IBA dozu uygulanan odun çeliklerinde 1.00 ve "köklenme yok" skala değerinde kalarak en düşük değeri vermiştir. Çeşit x IBA dozu interaksiyonu incelendiğinde ise Damaye kurt üzümü çeşidinden alınarak 1000 ppm IBA dozu uygulanan çeliklerin köklenme derecesi diğer uygulamalara nazaran 2.70 ile "köklenme yok-zayıf" aralığında kalarak daha yüksek olduğu tespit edilmiştir (Çizelge 3). Sadece çeşit bakımından köklenme dereceleri değerlendirildiğinde ise Damaye kurt üzümü çeşidinin 2.07'lik derece ile NQ7 kurt üzümü çeşidinden (1.56) daha iyi köklenme derecesi performansı gösterdiği saptanmıştır (Şekil 1). Köklenme derecesinin hesaplanmasında kullanılan kök sayısı, kök uzunluğu ile kök çapını etkileyen çelik alma zamanı (Çelik ve ark., 2015; Ruter, 2015), IBA dozu (Çelik ve ark., 2016; Ersoy ve ark., 2016), çeşit veya tip ile çelik tipi (basit ve ökçeli), çeliğin uzunluğu ve damızlık bitkinin yaşı da (Henry ve ark., 1992) köklenme derecesini etkileyebilecektir. Bu sebeple denememizden elde edilen köklenme dereceleri IBA dozu, çeşit ve çelik alma zamanlarından etkilenerek farklı seviyelerde olmuştur.

\section{Sonuç}

Sonuç olarak, kurt üzümü çeliklerinde zaman ve IBA dozlarının kök ve sürgün gelişimini olumlu veya olumsuz olarak etkileyebileceği, Damaye çeşidinden Ağustos ayında alınan ve 1000 ppm IBA uygulanmış olan yarı odunsu çeliklerdeki kök ve sürgün gelişiminin en yüksek değerlere ulaştığı, Aralık ayında alınan odun çelikleri ve kontrol veya 500 ppm IBA uygulamalarının ise kurt üzümü çeliklerindeki kök ve sürgün gelişimi bakımından olumsuz sonuçlar verdiği ortaya konulmuştur. Kurt üzümü çeliklerinde kök ve sürgün gelişimi bakımından çeşit olarak Damaye, çelik alma zamanı olarak Ağustos ayı ve doz olarak 1000 ppm IBA dozunun öne çıktığı saptanmıştır.

\section{Teşekkür}

Çalışmanın yürütülmesi aşamasında kurt üzümü bahçesini bizlere sunan, deneme materyallerini temin eden, deneme ortamı olan yüksek tünel ve sera içi alttan 1sıtmalı tavaları kurarak köklenme ortamını temin eden HZR Fidan, Tarım A.Ş'nin sahibi Sayın Mehmet ÇEKİL'e teşekkür ederiz.

\section{Kaynaklar}

Adrian, A., Valerica, T., Ionut, T.R., Alexandru, I., Violeta, Z., Daniel, T.A. 2016. Results on hardwood cuttings propagation of some lycium sp. genotypes. Fruit Growing, 32: 63-70.

Alsup, C. M., Cole, J. C. ve Claypool, P.L. 2004. Stem cuttings from caddo sugar maple trees differ in their rooting potential. Acta horticulturae. 630: 263-269. doi: 10.17660/ActaHortic.2004.630.32.

Anonim, 2015. Gojiberry Nasıl Yetişririlir. http://gojiberryorganik.com/index.php?s=icerik\&id=26 (Erişim Tarihi : 02.09.2019)

Anonim, 2016. Why we should grow goji berry. BioTree http://paulowniatrees.eu/learn-more/why-we-should-growgoji-berry/ (Erişim Tarihi:20.01.2016)

Beyl, C.A., Burger, D.W., Cheng Z-M. 2015. Plant Growth Substances Used In Propagation. Chapter 4, In: Introduction to Plant Propagation and Laboratuary Exercises (Ed: Beyl, C.A., Trigiano, R.N.), 47-63.

Brock, J.A., 2014. Rooting stem cuttings of shantung maple (Acer thuncatum), mound layering shantung and caddo sugar mapples (Acer saccharum) and using eastern redcedar (Juniperus virginiana) as a substrate component in stem cuttings propagation. MsC Thesis, Kansas State Univ., 95p.

Bryan, J. K., Costa, D., Giese, N., Nummy, K., Rapp, C., Seamon, E. 2008. Goji (Lycium spp) in natural standard monograph. Natural Standard.

Çelik, H., Çelik, D., 2017. Güzyemişi (Elaeagnus umbellata Thunb.) çeliklerinde köklenme üzerine çelik alma zamanı ve IBA dozlarının etkisi. BAHÇE 46 (Özel Sayı 1): 155-162.

Çelik, H., İslam, A., Kalkışım, Ö. 2015. Effect of cutting time and IBA application on rooting of edible cherry laurel (Prunus laurocerasus cv. 'Kiraz') cuttings. Anaolu Tarım Bilimleri Dergisi. 30:215-220.

Çelik, H., İslam, A., Kalkışım, Ö., Deligöz, H., Ateş, S., 2016. Karayemiş tepe çeliklerinin köklenmesi üzerine kesim şekli ve dışsal oksin uygulamasının etkileri. BAHÇE Dergisi, 45(1): 428-433. doi: 10.7161/anajas.2015.30.3.215-220. 
Çelik, H., Karasakal, Ö. 2018. Yayılıcı dağ muşmulası'nın (Cotoneaster horizontalis dnce.) tohum ve çelikle çoğaltılması. OMÜ Fen Bil. Enst. Yüksek Lisans Tezi, 180p.

Çelik, H., Yayla Çetin F., 2017. Süper meyve gojiberry (kurt üzümü). Köyüm Bitkisel Üretim ve Hayvancıllk Dergisi. 2(20): 76-80

Demchak, K. 2014. Goji Berry Culture. New York Berry News, 12(9): 27-28.

Ersoy, N., Kalyoncu, İ.H., Özer, N. 2016. Rooting of apical softwood cuttings of Cotoneaster horizontalis Decne with application of IBA and air humidity. Selçuk journal of agricultureand food sciences. 30:2, 67-73

Fukuda, T., Yokoyama, J. and Ohashi, H. 2001. Phylogeny and biogeography of the genus Lycium (Solanaceae): inferences from chloroplast DNA sequences. Molecular Phylogenetics and Evolution, 19(2): 246-58. Guo D.J., Cheng H.L., Chan S.W., Yu P.H.F. 2008. Antioxidative activities and the total phenolic contents of tonic Chinese medicinal herbs. Infl ammopharmacology, 16, 201-207.

Hartmann, H.T., Kester, D.E., Davies, F.T., Geneva, R.T. 2014. Plant Propagation. Principles and Practices. Pearson New Int. Ed. England, Eight Ed., 922p.

Levin, R. A., Miller, S. A., 2005. Relationships within tribe Lycieae (Solanaceae): paraphyly of Lycium and multiple origins of gender dimorphism. American Journal of Botany 92(12): 2044-2053. doi: 10.3732/ajb.9212.2044

Lonnee, D., Rose, D., Selinger, D., Whitman, J. 2011. Growing Shrubs and Small Trees in Cold Climets. Univ. Of Minnesota Press., 81-84.

Potterat, O. 2010. Goji (Lycium barbarum and L. chinense): Phytochemistry, Pharmacology and Safety in the perspective of traditional uses and recent popularity, Planta Med, 76, 7-19.

Ruter, J. 2015. Cloning Plants by Rooting Stem Cuttings. Chapter 17, In: Introduction to Plant Propagation and Laboratuary Exercises (Ed: Beyl, C.A., Trigiano, R.N.), s:219-229.

SPSS, (2017). IBM SPSS Statistics 25.0 for Windows. Armonk, NY.

Yılmaz, G., Kınay, A., 2016. Goji Beri (Lycium barbarum L.) Fidesi Üretimine Farklı Ortamların Etkileri. GOP Ziraat Fakültesi Dergisi, 33(1): 111-115.

Yılmaz G., Yıldız K., 2020. Bazı önemli dış mekan süs bitkilerine ait yeşil çeliklerin köklenme performansı. Akademik Ziraat Dergisi, 9(2): 373-380

Yi, R., Liu, X. and Dong, Q. (2013). A Study of Lycium barbarum polysaccharides (LBP) extraction technology and its anti-aging effect. African Journal of Traditional Complementary and Alternative medicine, 10(4): 171-174. doi: 10.4314/ajtcam.v10i4.27. eCollection 2013. 